\title{
AS CRÍTICAS DE HABERMAS AO PROJETO KANTIANO DE PAZ ${ }^{1}$
}

\section{HABERMAS'S CRITICISMS OF THE KANTIAN PEACE PROJECT}

\author{
Aylton Barbieri Durão*
}

Recebido: 05/2017

Aprovado: 10/2017

\begin{abstract}
Resumo: Habermas apresenta vários argumentos normativos que justificam a necessidade de uma reconstrução do cosmopolitismo kantiano: Kant desenvolveu um conceito negativo de paz, as alterações do projeto resultando em um cosmopolitismo fraco compatível com a soberania estatal, as concessões ao realismo político da razão de estado, a impossibilidade de conciliar a soberania estatal com os direitos humanos; além dos argumentos históricos que mostram como as condições que Kant considerou que fomentariam o cosmopolitismo (o pacifismo das repúblicas, do comércio internacional e a formação de uma opinião pública pacifista) sofreram uma espécie de dialética na medida em que, se em um primeiro momento, foram negadas pela evolução histórica, em um segundo momento, se realizaram parcialmente.
\end{abstract}

Palavras-chave: Habermas, Kant, paz, guerra, cosmopolitismo

\begin{abstract}
Habermas has several normative arguments justifying the need for reconstruction of Kantian cosmopolitanism: Kant developed only a negative concept of peace, the design changes resulting in a weak cosmopolitanism compatible with state sovereignty, grants to political realism of the status reason, the impossibility of reconciling state sovereignty to human rights; Besides the historical arguments that show the conditions that Kant considered that would promote cosmopolitanism (pacifism of the republics, international trade and the formation of a pacifist public opinion) experienced a kind of dialectic in that if at first, They were denied by historical evolution, in a second stage, partially realized. Keywords: Habermas, Kant, peace, war, cosmopolitanism.
\end{abstract}

\section{Introdução}

Em 1995, Habermas escreveu um artigo, inserido posteriormente em sua obra A inclusão do outro, comemorando os 200 anos de publicação do opúsculo de Kant Rumo à paz perpétua, no qual pretende, depois de uma análise crítica do projeto de paz kantiano, fazer uma reconstrução atualizada do cosmopolitismo. Habermas considera que o que Kant chamava de república ${ }^{2}$ possibilita uma forma de conexão entre democracia e direitos humanos, pois, a república é uma ideia da razão de acordo com o direito natural dos homens segundo o qual aquele que obedece a lei, o súdito, deve também ser o seu autor, na condição de cidadão, contudo, esta conexão somente pode ser promovida por um novo modo de organização jurídica, por isso, além do direito político, que rege as relações no interior do estado, e do direito das gentes, que regula as relações internacionais entre estados soberanos por meio de uma tensão constante entre guerra e paz, Kant introduziu uma novidade, o direito cosmopolita. Neste sentido, o direito internacional, no qual vige o estado de natureza, como um estado de guerra entre os estados soberanos, seria apenas uma etapa transitória das relações internacionais até que fosse institucionalizado o direito

\footnotetext{
* Departamento de Filosofia da Universidade Federal de Santa Catarina.

Problemata: R. Intern. Fil. v. 8. n. 3 (2017), p. 125-142 ISSN 2236-8612 doi:http://dx.doi.org/10.7443/problemata.v8i3.34060
} 
cosmopolita capaz de eliminar toda a guerra (HABERMAS, 1997, p. 192).

No entanto, do ponto do vista normativo, Habermas considera que o projeto kantiano padecia de quatro problemas resultantes de concessões feitas à política de seu tempo: o conceito negativo de paz motivado pela noção de guerra limitada baseada no equilíbrio das potências europeias, as contradições do projeto de paz que termina em um cosmopolitismo fraco compatível com a soberania estatal, o realismo político da razão de estado que interpreta a federação de estados como uma relação moral e não-jurídica entre os estados encobertada pelo mecanismo da história, a inconsistência do projeto de conciliar a soberania estatal com um conceito de direitos humanos realizável somente nas condições de uma democracia mundial; enquanto, da perspectiva histórica, as três indicações que Kant elaborou a partir de sua teoria do cosmopolitismo (o pacifismo das repúblicas, do comércio internacional e a formação de uma opinião pública pacifista) sofreram uma espécie de dialética na medida em que, se em um primeiro momento, foram negadas pela evolução histórica, em um segundo momento, se realizaram, ao menos parcialmente. Baseado nas críticas resultantes a ambas as perspectivas, Habermas pondera que o projeto cosmopolita precisa ser reconstruído de modo a poder responder as condições modernas.

\section{Os argumentos normativos}

Habermas afirma que Kant apresentou um conceito negativo de paz, mas nunca um conceito positivo, como é claramente expresso no veto da razão prática segundo o qual "não deve haver guerra" (HABERMAS, 1997, p. 193; KANT, MdS, p. 354). Existem duas razões para que Kant tenha defendido apenas um conceito negativo de paz, ainda que ambas remetam ao fato de que ele pensa o projeto de paz perpétua nas condições históricas do final do século XVIII.

Em primeiro lugar, Kant conhecia as guerras limitadas que surgiram em virtude dos vários tratados que compuseram a chamada Paz da Vestfália, que começou em $1648 \mathrm{com}$ a assinatura dos tratados de paz que puseram fim à Guerra dos 30 anos na qual o Imperador do Sacro Império e os Príncipes Eleitores entraram em conflito por causa da intolerância religiosa entre católicos e protestantes. A Paz da Vestfália ensejou um modelo de razão de estado no qual a soberania era internamente fortalecida pelo monopólio da violência legal concentrada nas mãos de um déspota que garantia da segurança interna, enquanto, externamente, os estados afirmavam a independência entre si, protegidos por um equilíbrio entre as potências europeias vigiado reciprocamente, que só permitia guerras limitadas realizadas 
de maneira prudente para não despertar os temores, dos demais estados, da busca da hegemonia, a qual poderia desatar uma aliança contra o transgressor, como acabou acontecendo com a França revolucionária, posteriormente. Estas guerras deveriam ser limitadas em vários sentidos: (1) deveriam envolver principalmente os exércitos regulares de estados nacionais que se enfrentariam no campo de batalha e poupar, na medida do possível, os não-combatentes; (2) deveriam ter objetivos específicos e bem delimitados, como a conquista de um território, a influência na sucessão ao trono ou a obtenção de algum recurso estratégico e; (3) deveriam ser demarcadas por uma declaração de início e um tratado decretando o fim das hostilidades.

Isto significa que Kant, como pensador do século XVIII, não conheceu a guerra total (HABERMAS, 1997, p. 194), cujo conceito foi desenvolvido pelos nazistas durante a Segunda Guerra Mundial ${ }^{3}$, na qual: (1) o uso de tecnologias de destruição em massa afeta indiscriminadamente toda a população envolvida; (2) passaram a existir outros tipos de conflitos que não envolviam exclusivamente a guerra entre os estados, como guerras civis, guerras de limpeza étnica, genocídios, guerras entre blocos de estados, guerra fria, cibernética, virtual, etc...; (3) os objetivos tornaram-se imprecisos, pois eram motivados por ideologias libertadoras que exigiam a destruição total do inimigo e; (4) eclodiam sem aviso prévio e permaneciam em estado latente, sem um acordo definitivo acerca do fim das hostilidades.

Como o conceito de paz de Kant é tão limitado como o próprio conceito de guerra (HABERMAS, 1997, p. 194), ele só leva em consideração apenas os aspectos econômicos da guerra e os males morais que causa, por isso, pretende regular o conflito condenando medidas que tornariam impossível a confiança recíproca com vistas a uma paz futura como o uso de envenenadores ou assassinos (KANT, ZeF, p. 346), mas não aborda o tema dos horrores e sofrimentos causados pela guerra, os refugiados, os campos de concentração, os feridos e, sobretudo, os mortos em genocídios cada vez mais frequentes. A condenação destas práticas permite a Habermas afirmar que Kant as considerava crimes de guerra, no entanto, embora Kant inclua o veto a estas ações entre os artigos preparatórios à paz perpétua, ele não prevê efetivamente nenhuma pena para quem as realiza, o que seria de esperar para que uma ação fosse considerada um crime de guerra. De qualquer modo, mesmo que Kant aceitasse que estas ações constituem crimes de guerra, Habermas assinala que, por não conhecer o conceito de guerra total, ele não criminaliza a própria guerra (HABERMAS, 1997, p. 195), como podem ser interpretadas algumas resoluções atuais das Nações Unidas.

Em segundo lugar, Kant desenvolveu apenas um conceito negativo de paz porque, como filósofo do século XVIII: (1) pensava a-historicamente e não levava em consideração as condições culturais, sociais e econômicas que são 
as causas da guerra e que precisam ser combatidas em um projeto que fomente positivamente a paz (HABERMAS, 1997, p. 215) e; (2) além disso, o modo como ele imaginou o cosmopolitismo dispensava a necessidade de pensar uma mudança positiva nas condições da paz porque ele concebeu que, se o acaso permitiu que um povo poderoso e ilustrado fizesse uma revolução que instaurou a constituição republicana, então, à medida que outros estados também fizessem reformas que conduzissem à constituição republicana, eles se aglutinariam ao redor do primeiro formando uma federação pacífica de estados (HABERMAS, 1997, p. 213).

Embora Kant não diga explicitamente, ele imaginava que a federação de estados surgiria a partir da República inaugurada na França pela Revolução Francesa (KANT, MdS, p 323), não obstante, os acontecimentos históricos caminharam em outra direção e, ao longo do século XX, as Nações Unidas passaram a ser principal organização cosmopolita, mas ela congrega uma associação de estados em condições políticas, sociais e econômicas muito diferentes, o que, ao contrário do que ocorria no tempo de Kant, obriga a pensar no problema da compatibilidade a respeito destas condições.

Habermas atualiza a divisão entre mundos depois da derrocada do socialismo real e classifica os estados em três grupos: (1) o Terceiro Mundo é formado por aqueles países em que os governos se tornaram tão frágeis que já não conseguem regular a própria sociedade e tem que competir pelo poder com organizações criminosas, como os narcotraficantes, os paramilitares; (2) o Segundo Mundo é constituído pelos estados que dispões de um forte controle do monopólio da violência legal nas mãos das autoridades e que afirmam taxativamente a sua independência externa frente a outros estados; (3) enquanto somente os países do Primeiro Mundo, caracterizados pela sensibilidade política para uma esfera pública, na qual os cidadãos se expressam, e pela simpatia com a regulação das relações internacionais mediante organismos supraestatais, dispõem das condições positivas para a paz (HABERMAS, 1997, p. 214-5).

Consequentemente, torna-se necessário avaliar a complexidade de causas da guerra para oferecer uma alternativa para a paz, sem o recurso da violência, capaz, não apenas de preveni-la, mas de constituir uma relação entre povos isenta de tensões. Por isso, as regulamentações para a solução de conflitos não podem vulnerar a existência, a autoestima, os interesses vitais e a sensibilidade das partes a ponto de despertar novamente a violência mas devem usar todos os recursos disponíveis, abaixo do limite do emprego direito de forças armadas, com o intuito de fomentar as condições econômicas e sociais capazes de promover o desenvolvimento da tolerância, dos direitos humanos, da democracia e do estado de direito (HABERMAS, 1997, p. 216).

Embora alcançar a paz seja um resultado importante, ela, contudo, é 
apenas um sintoma do projeto cosmopolita de paz e, portanto, torna-se necessário descrevê-lo de modo a compreender a sua diferença com relação ao direito internacional clássico, porém, a posição de Kant oscila consideravelmente no decorrer do tempo. Segundo o modelo da teoria contratualista, o estado de natureza se caracteriza pela ausência de um poder coativo estatal e, como consequência da influência de Hobbes, Kant o considera como um estado de guerra de todos contra todos (KANT, RGV, p. 97). Contudo, deve-se distinguir as quatro situações em que pode ocorrer o estado de natureza: em uma suposta condição inicial do homem em que os indivíduos se encontram isolados entre si na ausência tanto de uma associação horizontal, a sociedade, como vertical, o estado; com relação àqueles objetos ou pessoas que não se encontram em uma relação jurídica, como ocorre com as águas ou o ar, por um lado, ou entre os habitantes nativos da América, por outro ${ }^{4}$; quando ocorre o intervalo na soberania provocada por uma revolução em que o soberano anterior é destituído e, finalmente; na relação em que os estados se encontram entre si, por causa da inexistência de um poder coativo supraestatal. Em Ideias para uma história universal em sentido cosmopolita, de 1784, e Teoria e práxis, de 1793, Kant apresenta um cosmopolitismo forte resultante da analogia perfeita entre indivíduos e estados (HABERMAS, 1997, p. 196), ou seja, assim como os indivíduos se submeteram, por meio do contrato originário, a um poder soberano na medida em que aceitaram a sua entrada no estado civil, os estados devem aderir a um estado cosmopolita universal (ein allgemeiner weltbürgerlicher Zustand) (KANT, IGA, p. 28) dotado de um poder unificado, cujas leis provêm de uma vontade comum (KANT, IGA, p. 24) e que seja capaz de obrigar os estados membros, haja visto que o chamado equilíbrio das potências europeias é uma quimera como a casa de Swift, construída tão perfeitamente segundo as leis do equilíbrio que bastou um simples pardal pousar sobre ela que toda a construção desabou (KANT, TuP, p. 312). Por conseguinte, o direito internacional, baseado na independência entre estados soberanos, valeria somente de modo transitório, até que fosse substituída por um direito cosmopolita que regulasse as relações interestatais.

Não obstante, em seus últimos trabalhos, tanto em Rumo à paz perpétua, de 1795, como $A$ doutrina do direito, de 1797, Kant muda de perspectiva e passa a defender um cosmopolitismo fraco no qual existe uma analogia imperfeita entre indivíduos e estados distinguindo claramente um estado de povos de uma federação de estados que pode ser resumido em três argumentos: (1) segundo o argumento político, um estado de povos incidiria em uma monarquia universal e como a lei precisa ser compensada pelo uso da força quando aumenta a extensão territorial, então, esta recairia inicialmente no mais cruel dos despotismos, enquanto pudesse ser imposta, mas que, por fim, terminaria em uma anarquia, quando não se conseguisse mais impô-la (KANT, 
ZeF, p. 367); (2) de acordo com o argumento jurídico, estados podem ser parcialmente comparados com indivíduos porque se encontram em estado de natureza sem lei, o que pode demandar que eles se submetam a uma organização comum semelhante a uma constituição civil, contudo, diferentemente do indivíduos, os estados já estão submetidos ao direito político e à lei, no plano interno, por isso, bastaria que os soberanos fizessem reformas internas até alcançar a constituição republicana, a única que fomenta a paz na medida em que o súdito, que também desempenha o papel de cidadão dificilmente daria o seu consentimento a um empreendimento tão maléfico para os seus próprios interesses (KANT, ZeF, p. 351) e; (3) com base no argumento lógico, um estado de povos implicaria uma contradição porque seria uma forma de realização do direito internacional que somente se realizaria pela supressão do próprio direito internacional, na medida em que todos os povos seriam submetidos a um único soberano, mas, nesse caso, o direito internacional se converteria em direito interno ao próprio estado, o chamado direito político (KANT, ZeF, p. 354). Esta federação de estados deveria deixar, portanto, intacta a soberania dos estados membros, pois, em lugar de ideia positiva de uma república mundial no qual os povos seriam submetidos a uma legislação e poder coativo comuns, haveria o sucedâneo negativo de uma federação protetora frente à guerra. Neste sentido, a federação de estados seria somente uma associação permanente de estados que pode ser dissolvida a qualquer momento, por isso, Kant critica justamente 0 caráter indissociável da Constituição dos EUA (KANT, MdS, p. 351).

Habermas, contudo, que é mais simpático ao projeto inicial de um cosmopolitismo forte baseado na reconstrução da ONU faz três críticas ao modelo kantiano definitivo. Em primeiro lugar, o projeto final é contraditório porque Kant ora afirma que o congresso de estados é permanente ora que pode ser dissolvido a qualquer momento (HABERMAS, 1997, p. 196); além do mais, como Kant pretende formar uma federação para a paz que simultaneamente salva a soberania dos estados, então, não existe uma relação propriamente jurídica entre os estados membros, já que eles não precisam se submeter à legislação e coação de uma organização supraestatal, por isso, a única razão para a manutenção desta associação é a autovinculação moral dos governos, o que é profundamente instável, como demonstrou a Sociedade de Nações entre as duas Guerras Mundiais (HABERMAS, 1997, p. 197) e; por último, dadas as próprias observações kantianas sobre a política de seu tempo, o despotismo dos soberanos, a situação de guerra endêmica, o jesuitismo dos moralistas políticos, etc..., carece de realismo desenvolver um projeto de paz compatível com a preservação da soberania estatal (HABERMAS, 1997, p. 198).

Segundo Habermas, o próprio Kant percebeu o problema em uma 
declaração na qual afirma que não deve haver guerra entre os estados, embora ele não deva existir nenhum poder legislativo que assegure o meu e o seu direito, por isso, não se consegue entender onde ele quer basear a sua confiança no direito já que não existe nenhuma outra alternativa à federação de estados independentes, mas, em seguida, encobre esta dúvida com uma confiança na capacidade da razão em estabelecer esta associação permanente de estados como resultado do direito das gentes. Contudo, se a federação de estados deve ser uma construção jurídica e não apenas moral, capaz de regular a relação entre os estados no sentido de evitar a guerra, então, tornase necessário mostrar os institutos legais semelhantes aos que existem em uma constituição, como ocorre no interior dos estados, capaz de preservar a autovinculação permanente dos estados membros e não simplesmente esperar que este resultado surja da boa formação moral de seus membros (HABERMAS, 1997, p. 199).

Habermas observa, contudo, que Kant acabou por propor o cosmopolitismo fraco de uma federação de estados baseado na mera associação permanente de estados soberanos porque cedeu ante o realismo político de seu tempo que imperou durante o período da Paz da Vestfália (VELASCO, 1997, p. 109). Enquanto o modelo republicano advindo da Revolução Americana e da Revolução Francesa ${ }^{5}$ representavam exceções, o realismo político da Modernidade estava fundamentado em uma razão de estado que defendia o equilíbrio das potências europeias com base na soberania estatal, uma vez que reconhecia que somente estados soberanos poderiam ser agentes nas relações internacionais, na medida afirmava a sua soberania, no plano interno, mediante o monopólio da violência legal retido nas mãos de um déspota esclarecido, que deveria garantir a segurança e a ordem por meio do direito positivo e do poder político, com vistas ao fim principal que consistia em afirmar a soberania no plano externo mediante o uso do poder militar em uma política de expansão constante, através de guerras prudentes que não despertassem a suspeita dos demais estados de uma busca da hegemonia que pusesse em risco o equilíbrio de poder proveniente dos acordos de paz do século XVII.

Diante do quadro da razão de estado vigente durante a Paz da Vestfália Habermas tira três conclusões sobre o projeto kantiano de paz perpétua: (1) o projeto de paz instituído por um cosmopolitismo forte fundado em uma constituição cosmopolita que estabelecesse uma legislação e poder coativo comum que subordinasse os estados esbarraria na reivindicação de autoafirmação interna e externa destes estados e, portanto, não seria realista, por isso, Kant acabou reformulando o projeto de paz inicial em que propunha uma constituição republicana cosmopolita de caráter supraestatal de suas primeiras obras pelo modelo mais fraco de uma federação de estados 
permanentes, mas que pode ser dissolvida a qualquer momento, estruturada sobre a soberania dos estados independentes; além do mais, isso explica também porque Kant passou a temer que o seu modelo inicial de um cosmopolitismo forte baseado em uma federação de povos originasse uma monarquia universal, pois, diante da razão de estado da Modernidade, a autoafirmação interna exigia a garantia da segurança e da ordem internas mediante a estrita observância do exercício do direito positivo e do poder de polícia de déspotas esclarecidos, os quais somente eram amenizados pelo espírito de liberdade que tinham que conceder a seus súditos diante da necessidade de permitir um progresso econômico capaz de alimentar, com impostos, a voracidade sempre crescente das guerras provenientes da política externa de expansão; como Kant não podia mais defender uma cosmopolitismo forte baseado em um estado de povos porque acabou cedendo ao realismo político de sua razão de estado e terminou propondo o cosmopolitismo fraco de uma federação de estados, então, também não podia esperar que houvesse uma organização jurídica que regulasse as relações entre os estados meramente associados, consequentemente passou a acreditar na capacidade da razão em concretizar o que era estabelecido pelo direito das gentes. $O$ problema é que também não se poderia confiar inteiramente na capacidade da razão, devido a sua impotência com relação aos obstáculos empíricos, por isso, Kant teve que introduzir uma filosofia da história que mostrava como o mecanismo da natureza, servindo-se do antagonismo da insociável sociabilidade, por um lado, e das próprias guerras, por outro, se encarregavam de realizar o ideal da paz perpétua, com base no adágio estoico de que o destino guia os que se submetem, mas arrasta os que resistem (HABERMAS, 1997, p. 199).

No entanto, Habermas considera que o projeto cosmopolita kantiano que pretende preservar da soberania dos estados por meio de uma federação de estados é contraditório com os fundamentos de seu pensamento a respeito do próprio direito. Habermas entende que, para Kant, todo o direito provém do único direito inato do homem à liberdade, que o homem possui em função unicamente de sua humanidade, a partir do qual Kant obtém o princípio do direito que estabelece que o livre arbítrio de cada um deve concordar com o livre arbítrio de todos os demais, segundo uma lei universal da liberdade, portanto, ele fundamentava toda a relação jurídica, e não apenas aquela que está submetida à soberania do estado, no direito à liberdade que todo indivíduo possui unicamente por causa de sua qualidade de "ser humano". Por isso, Habermas afirma que a fundamentação dos direitos em geral nos direitos humanos confere a todo o ordenamento jurídico moderno, e não apenas aos direitos fundamentais que protegem a pessoa humana, um traço inegavelmente individualista. Então, se o direito em geral, e não apenas aquele que depende 
do estado, provém do direito humano à liberdade, então, a garantia dos direitos humanos exigiria uma organização política cosmopolita semelhante a um estado de povos e não uma mera associação permanente, e passível de dissolução, de estados soberanos independentes entre si. Afinal de contas, a violação da justiça em uma parte do mundo afeta a todos os demais seres humanos. Além do mais, Kant estabelece uma conexão entre os direitos humanos e a soberania popular, pois a constituição republicana é a única que está em consonância com os direitos naturais do homem, ou seja, que aqueles que devem obedecer às leis devem também ser os legisladores, os autores das leis. Consequentemente, a garantia dos direitos humanos, implica a necessidade de uma cidadania mundial e a consecução da paz, que depende da realização das três figuras do direito público, o direito político, o direito das gentes e o direito cosmopolita, e da qual se aproximaria constantemente, exigiria a promulgação de uma legislação cosmopolita na qual a autonomia dos cidadãos do mundo não fosse mediada pela soberania dos seus estados (HABERMAS, 1997, p. 210).

Habermas, então, considera que a garantia dos direitos humanos exige a formação de uma cidadania mundial na qual os sujeitos jurídicos individuais estabeleçam uma relação direta com uma organização cosmopolita sem a mediação dos estados particulares, consequentemente, haveria uma dupla cidadania, pois, os indivíduos seriam, por um lado, cidadãos de um estado particular com atribuições específicas e uma cidadania mundial com competências próprias. Na verdade, como a transgressão dos direitos humanos, em geral, ocorre da parte dos próprios estados, caberia a esta cidadania mundial da organização cosmopolita passar por cima dos governos estatais e onde se destacaria mais a sua competência seria justamente na atribuição de responsabilidade àqueles servidores estatais que cometessem crimes a serviço do estado (HABERMAS, 1997, p. 210).

Ainda que de forma incipiente, Habermas assinala que a evolução das relações internacionais, ao longo do século $X X$, ultrapassou a perspectiva do projeto kantiano de limitar o cosmopolitismo pela soberania dos estados, pois, sobretudo depois da fundação da ONU e a promulgação da Declaração Universal dos Direitos do Homem, em 1948, a qual foi seguida de uma série de resoluções complementares, passou a existir um controle internacional sobre a violação de direitos a nível global. Na maioria dos casos as resoluções da ONU são ratificadas pela legislação dos estados nacionais e, nesse sentido, passam a ser direito positivo no interior destes estados, mas Habermas considera mais relevantes justamente aqueles casos em que a ONU passa por cima dos próprios estados para a garantia dos direitos humanos, na medida em que eles são reveladores da formação de uma legislação e capacidade coativa da organização com caráter cosmopolita (VELASCO, 1997, p. 111). Como a ONU 
nem sempre confia na boa intenção ou na capacidade dos estados para implementar as suas resoluções, então, ela dispõe de organismos e observadores para detectar as violações dos direitos humanos, enquanto que, para os direitos sociais, ecológicos e culturais possui órgãos de supervisão e, para os direitos civis e políticos, estabeleceu procedimentos de reclamação. Embora estes instrumentos tenham muito mais a capacidade de avaliar as transgressões de direitos do que agir diretamente contra os estados nacionais, Habermas considera que eles são suficientes para assinalar o avanço do cosmopolitismo na direção de uma regulação supraestatal das relações internacionais e ele afirma que o caso do julgamento dos crimes de guerra cometidos pelos nazistas no Tribunal de Nuremberg não constitui uma exceção incapaz de formar uma jurisprudência ${ }^{6}$, mesmo apontando que a Assembleia Geral da ONU unicamente promulgou diretrizes que servem como princípios para um direito internacional apto para julgar os crimes de guerra (HABERMAS, 1997, p. 211).

Além do mais, todos esses esforços, esbarram na posição das Nações Unidas de considerar insuperável o respeito pela soberania dos estados membros, o que enfraquece a garantia dos direitos humanos consubstanciados na Declaração dos Direitos do Homem, já que, na maioria dos casos, eles devem ser protegidos contra violações perpetradas pelos próprios estados contra a sua população. No entanto, Habermas assinala que, também neste caso, a posição das Nações Unidas começa a mudar de direção, uma vez que na Guerra do Golfo, em 1991, a ONU estabeleceu zonas de exclusão aérea no território iraquiano com vistas a proteger principalmente a minoria curda ameaçada de genocídio pelo governo do Iraque.

\section{A dialética dos argumentos históricos}

Habermas ressalta que Kant extraiu de sua concepção de história a priori, narrada a partir dos pressupostos da razão, uma série de argumentos que indicavam a aproximação constante em direção à paz perpétua. Não obstante, as indicações apresentadas por Kant em sua história filosófica experimentaram uma espécie de dialética, porque, se em um primeiro momento, os acontecimentos históricos ocorridos nos séculos XIX e XX apontavam na direção contrária ao que ele havia assinalado, em um segundo momento, elas começaram a concordar, ao menos parcialmente, com as suas observações, o que justifica a necessidade, não tanto de prosseguir o projeto do cosmopolitismo kantiano, mas de uma reformulação adequada às condições atuais (HABERMAS, 1997, p. 199).

O primeiro deles expõe o caráter pacífico das repúblicas. Segundo Kant, 
existe um progresso nas formas de governo, os quais começam quando um usurpador reúne a multidão selvagem para formar um povo, mas, pela pressão do antagonismo da insociável sociabilidade e pela necessidade de gerar um espírito de liberdade para custear, através de impostos, a guerra futura, o soberano se converte em um déspota esclarecido, o qual governa de forma republicana, como se as leis emanassem da vontade do próprio povo, ainda que o povo não seja efetivamente consultado, neste sentido, a sua época ainda não é esclarecida, mas é um tempo de esclarecimento (KANT, BdF, p. 40), contudo, pelas mesmas razões históricas o espírito da constituição republicana se refletirá também na sua letra e esta se aproximará da forma republicana de governo na qual o povo unido dará a legislação para si próprio (KANT, MdS, p. 340). Na medida em que se aproxime da constituição republicana em que o súdito, aquele que obedece a lei, será também um cidadão, o autor da lei, o estado tende a se tornar pacífico porque, como são os próprios cidadãos que devem decidir sobre a guerra, cujos males e custos eles têm que pagar, então, dificilmente dariam o seu consentimento a uma situação tão penosa (KANT, ZeF, p. 351). Nesta mesma direção, deve ocorrer o fim dos exércitos permanentes, que Kant denomina de mercenários, uma vez que são soldados pagos para lutar, porque isso é contrário à fórmula da humanidade do imperativo categórico, que estabelece que deve-se tratar a humanidade na tua pessoa e na pessoa dos demais, ao mesmo tempo, sempre como um fim em si mesmo e nunca meramente como um meio, por isso, eles devem ser substituídos por milícias permanentes de cidadãos que fazem exercícios voluntários e regulares para que estejam preparados para defender a pátria (KANT, Zef, p. 345). Apesar da linguagem, Habermas considera que Kant não poderia prever o desenvolvimento do nacionalismo nos séculos $X I X$ e $X X$, o qual contribuiu significativamente para transformar o súdito em cidadão, uma vez que gerou uma associação entre cidadania e nacionalidade, pois a participação política dos cidadãos passou a vincular-se com o sentimento de exaltação do pertencimento a uma nação. Este fenômeno, contudo, conduziu o civismo dos cidadãos na direção oposta àquela esperada por Kant porque fomentou um sentimento de que a verdadeira cidadania se encontrava na disposição para lutar e morrer pela pátria em guerras conduzidas em nome da defesa da liberdade entendida como autodeterminação nacional, por isso, as milícias de cidadãos, longe de impelirem ao ideal da paz perpétua e ao respeito ao imperativo categórico, deram lugar ao serviço militar obrigatório, no qual corações e mentes eram manipulados com o propósito de insuflar o ideal de defesa da pátria, na maioria das vezes, escondendo interesses particulares. Neste sentido, o estado nacional contemporâneo substitui o estado absolutista moderno, mas não se tornou mais pacífico, porque simplesmente substituiu a ideologia das guerras limitadas e prudentes resultantes da autoafirmação da 
própria soberania interna e externa pela autoafirmação da identidade nacional através de guerras de autodeterminação (HABERMAS, 1997, p. 200).

A situação se modificou, contudo, depois da Segunda Guerra Mundial quando o nacionalismo amainou, pelo menos nos países desenvolvidos onde vigora o estado democrático de direito, o que permitiu o surgimento de uma noção mais democrática de cidadania. Isto não implicou que as repúblicas tenham se tornado mais pacíficas, pois, estatisticamente, elas não se envolvem em menos guerras que os estados submetidos a governos autoritários, mas que houve uma mudança significativa nas suas relações internacionais. Em primeiro lugar, os países caracterizados como estados democráticos de direito passaram a ter relações pacíficas entre si e resolver os seus conflitos com outros meios diferentes da guerra, sobretudo através da autorregulação jurídica mediante a ratificação interna de tratados e acordos internacionais. Embora os estados democráticos de direito continuassem a utilizar a guerra como instrumento para solução de conflitos contra estados autoritários, também houve uma modificação na perspectiva de ação, em primeiro lugar, porque, igualmente neste caso, houve um aumento da busca pela legitimação internacional. Esta legitimação ocorre em diferentes níveis, a formação de uma opinião pública mundial em torno da necessidade da intervenção, a condenação de ações de governos autoritários em distintos organismos internacionais, a formação de alianças entre o maior número possível de estados envolvidos na intervenção, etc...ainda que, até o presente momento, a ONU jamais tenha autorizado a intervenção em um estado soberano. Em segundo lugar, os estados democráticos de direito passaram a justificar a intervenção com base na intenção de promover os ideais de democracia e direitos humanos nos casos de graves ofensas a estes princípios por parte dos estados submetidos a governos autoritários (HABERMAS, 1997, p. 200).

Houve também uma espécie de dialética no segundo argumento kantiano sobre o caráter pacifista do comércio internacional, pois, se em um primeiro momento, ao longo do século XIX e primeira metade do século XX, 0 progresso econômico dos países capitalistas conduziu a um aumento considerável dos conflitos, em um segundo momento, as mudanças ocorridas depois da Segunda Guerra Mundial contribuíram para que a economia submetesse o poder do estado, embora em um sentido oposto ao do que Kant acreditava, pois, em lugar do seu fortalecimento, os imperativos atuais de uma economia globalizada estabelece uma interdependência mundial que solapa a soberania dos estados e desvanece a nitidez da separação entre política interior e exterior (HABERMAS, 1997, p. 201).

Kant considerou que as guerras desempenhavam, contraditoriamente, um papel importante na realização do projeto de paz entre os estados na medida em que os governantes necessitavam de um aumento crescente de 
recursos para custear a guerra futura; isto os obrigava a permitir um espírito de liberdade indispensável para o aumento da riqueza e o consequente pagamento de impostos. Enquanto os governos contavam apenas com os recursos de seus súditos havia um freio natural para as guerras representado pela capacidade de arrecadação de impostos do estado, contudo, Kant nota que em seu tempo surgiu uma nova invenção ${ }^{7}$ a formação de um sistema financeiro internacional que amplia a capacidade de endividamento do estado para custear as guerras, razão pela qual elas perderam os seus limites e a situação de sua época é de que as guerras se tornaram uma endemia (KANT, ZeF, p. 345). Contudo, justamente este sistema financeiro internacional contribui para a aproximação assintótica da paz na medida em que gera uma interdependência entre os estados e, uma vez que a bancarrota de um estado arrasta consigo todos os demais, então, acabará por surgir um mecanismo de regulação nas relações interestatais capaz de evitar as crises econômicas que conduzirá gradualmente a uma federação de estados, conforme expressa o direito das gentes (KANT, IGA, p. 28).

Seguindo uma interpretação da história de viés marxista, Habermas observa, entretanto, que Kant, como pensador do século XVIII, não poderia perceber os efeitos do progresso do capitalismo nos séculos seguintes, como o fez Hegel a partir da economia política clássica de Adam Smith e David Ricardo. O desenvolvimento do capitalismo, longe de contribuir para a paz, levou a uma série de novas formas de violência, pois, por um lado, o acirramento da divisão e do conflito de classes sociais entre o proletariado que vendia a sua força de trabalho e a burguesia detentora dos meios de produção, dentro do estado, foi exportado para o exterior mediante guerras que, aliadas ao fenômeno do nacionalismo, serviam para encobrir a tensão de classes mediante uma falsa totalidade representada pela unidade nacional contra um inimigo estrangeiro em comum, enquanto que, por outro, a necessidade crescente de matérias-primas e de mercados consumidores, formaram as condições para o aparecimento do imperialismo, que levou a uma brutal colonização da África e da Ásia, bem como às duas Guerras Mundiais (HABERMAS, 1997, p. 201).

Não obstante, depois da Segunda Guerra Mundial ocorreram dois fenômenos que contribuíram paralelamente para modificar estas fontes de conflito, pois, enquanto o desenvolvimento do estado do bem-estar social amainou o conflito de classes na medida em que os trabalhadores puderam desfrutar de direitos trabalhistas e previdenciários, bem como uma melhoria de suas condições sociais e econômicas, houve um arrefecimento do nacionalismo, portanto, pelo menos nos países desenvolvidos ${ }^{8}$, onde vigora 0 estado democrático de direito, ocorreu um avanço em direção à paz, o que parece indiretamente confirmar a tese kantiana sobre o caráter pacifista do 
comércio internacional (HABERMAS, 1997, p. 202).

Contudo, o fenômeno da globalização, caracterizado por uma relação de interdependência no intercâmbio de mercadorias e pela formação de redes de comunicação a nível planetário, que se desenvolveu no final do século $X X$, apontou em uma direção oposta àquela pensada por Kant, porque a economia passou a domesticar as forças da política ao mesmo tempo em que, simultaneamente, reduzia a importância do estado nacional e alterava as relações entre a política interna e externa. O estado nacional já não é mais capaz de regular as relações econômicas exclusivamente com a legislação e o poder coativo que detinha no passado, quer porque muitos bancos e empresas multinacionais dispõem de mais riqueza que a maioria dos estados, quer porque a própria globalização permite uma rápida fluidez de capitais que podem ser transferidos para outros lugares diante de políticas indesejadas promovidas pelos governos nacionais, quer porque a promoção do bem-estar coage a própria cidadania aos imperativos do sistema econômico. Além do mais, a globalização também ameaça a diferenciação clássica entre política interna e externa, seja por causa da ingerência indireta dos agentes econômicos estrangeiros privados, seja pela intervenção branda de agências públicas ou semipúblicas na tomada de decisão de governos nacionais (HABERMAS, 1997, p. 202).

Do mesmo modo, o terceiro aspecto que Kant assinalou que contribuiria historicamente para a aproximação da paz perpétua, o conceito de publicidade, sofreu um processo dialético, primeiramente negando, e depois confirmando parcialmente as suas expectativas. Desde Mudança estrutural da esfera pública, de 1961, que Habermas sustenta a tese de que o conceito kantiano de publicidade deveria ser interpretado em um sentido mais amplo, indicando que o filósofo de Königsberg haveria antecipado a noção de opinião pública, limitada evidentemente a um público culto de membros da classe burguesa, reunidos em salões reservados para discussões literárias, os quais, entretanto, formariam uma esfera pública capaz de julgar as decisões dos governantes segundo o princípio transcendental de publicidade de suas máximas, uma vez que não pode ser legítima uma máxima que não possa ser expressa publicamente (HABERMAS, 1995, p. 178). Além do mais, existem outras obras de Kant que também indicam a importância do tema da publicidade. Em Resposta à pergunta: o que o esclarecimento?, a partir da diferenciação entre o uso privado da razão, que consiste em fazer uso de sua razão em uma instituição específica, onde o indivíduo está limitado pelos regulamentos da própria instituição, e o uso público da razão, no qual o indivíduo, na condição de sábio, pode se dirigir à todos os demais, inclusive para criticar aquela instituição particular da qual faz parte, desde que, naturalmente, a discordância não seja tão radical que ele não pode mais integrá-la, que Kant recorda a 
importância da reflexão dirigida a um público em geral para o esclarecimento, ainda que a culpa da menoridade seja de cada indivíduo porque, por preguiça e covardia, ele prefere aceitar as opiniões dos tutores da grande massa que the dizem o que pensar; por isso, o esclarecimento, para Kant, é negativo, e se os tutores deixarem o público em paz é inevitável que eles se esclareçam a si mesmos (KANT, BdF, p. 36). Também no "Segundo Suplemento" à Rumo à paz perpétua, Kant observa que deve existir apenas uma única cláusula secreta nos tratados de paz, aquela que permita aos filósofos falarem pública e livremente sobre os princípios da guerra, porque eles são incapazes de adotar o ponto de vista de facções ou clubes, pela própria natureza da atividade, e, portanto, não podem gerar a suspeita de fazer propaganda ou proselitismo (KANT, ZeF, p. 368). Por fim, em Teoria e práxis Kant afirma que se deve conceder a liberdade de pluma para os cidadãos leais e fieis para que colaborem com o soberano na interpretação da vontade unificada do povo, porque, se a vontade geral não pode errar, o governante, que ocupa a posição do soberano, pode se equivocar na sua interpretação e, contrariamente ao que pensava Hobbes, pode cometer injustiças contra o povo (KANT, TuP, p. 304).

Habermas observa que as esperanças de Kant com a opinião pública inicialmente não aconteceram, em primeiro lugar, porque o seu otimismo com a capacidade da razão é fruto da confiança iluminista do século XVIII, a qual foi desacreditada no século XIX (HABERMAS, 1997, p. 204), com Marx que demonstrou que o que aparentemente é um produto da razão, na verdade, é uma ideologia que esconde o interesse de classes, com Nietzsche que indicou que a razão é apenas outra forma de expressão da vontade de poder e com Freud que mostrou que a razão recalca e oblitera as manifestações do inconsciente; em segundo lugar, porque, ao contrário do que Kant pensara, no século XX, os filósofos cometeram a "grande traição", uma referência ao fato de que o pensamento filosófico acabou tendo um engajamento político, como atestado pela teoria dos intelectuais orgânicos de Gramsci; em terceiro lugar, porque o conceito de opinião pública de Kant era restrito a um público literário e limitado a uma classe privilegiada social, econômica e culturalmente, enquanto a esfera pública evoluiu para incluir um público profundamente apático, dominado pela comunicação de massas e suscetível à manipulação ideológica e comercial de grupos formadores de opinião.

Contudo, a partir de uma referência de Kant em que ele menciona exclusivamente o fato de que a transgressão do direito em uma parte do mundo afeta a todo o restante (KANT, ZeF, p. 360), Habermas a extrapola e complementa, indicando que Kant já havia antevisto, com esta declaração, a formação de uma opinião pública global, a qual contribuiu, ainda que parcialmente, para a mudança sobre a opinião a respeito da guerra. Habermas considera que, apesar do caráter incipiente de uma esfera pública a nível 
nacional, e muito mais precária a nível global, os dois momentos em que ela se manifestou, inicialmente, foram com relação â guerra do Vietnam e do Golfo, embora mais recentemente a ONU esteja realizando anualmente conferências mundiais sobre fenômenos que afetam a todos os seres humanos, começando com a Conferência Mundial da Criança em Nova York, em 1990. Além do mais, algumas organizações não governamentais também têm demonstrado capacidade para mobilizar uma opinião pública global e chamar a atenção para problemas planetários, como o Greenpeace ou a Anistia Internacional. Contudo, mais importante no que se refere ao projeto de paz foram os vários tratados internacionais e as organizações que surgiram como decorrência da tentativa de controle das guerras, em parte motivadas pela opinião pública horrorizada com o descontrole das guerras totais em termos de sofrimento e vítimas humanas (HABERMAS, 1997, p. 205). Portanto, embora Habermas observe que, também neste aspecto, a indicação kantiana sobre o papel pacificador da opinião pública tenha, ao menos em parte, se confirmado, ele conclui recordando que a taxativa distinção da filosofia transcendental entre o a priori e o empírico não permitiu que o filósofo de Königsberg percebesse o potencial de aprendizagem para a solução de problemas existente nesta ideia e acabou relegando para a intenção da metafísica da natureza a tarefa de explicar como um acordo social urdido patologicamente poderia se transformar em uma totalidade moral (HABERMAS, 1997, p. 206).

\section{Referências:}

Aramayo, R. (org). La paz y el ideal cosmopolita de la llustración: a propósito del bicentenario de "Hacia la paz perpetua" de Kant. Madrid: Tecnos, 1996

BENHABIB, S. Kosmopolitismus und Demokratie: Von Kant zu Habermas. Goethe-Institut e. V., Fikrun wa Fann, Juni 2012. Disponível em: <http://www.goethe.de/ges/phi/prj/ffs/the/a97/de9507770.htm>. Acesso em 28 de fev. 2017.

BOHMAN, J. \& LUTZ-BACHMANN, M. Perpetual peace: essay on Kant's cosmopolitism ideal. Massachusetts: The MIT Press, 1997.

CONTRERAS PELÁEZ, F. C. Kant y la guerra: una revisión de la Paz Perpetua desde las preguntas actuales. Valencia: Tirant lo Blanch, 2007.

FINE, R. \& SMITH, W. Jürgen Habermas's Theory of Cosmopolitanism. Constellations, 10(4):469-487, 2003. 
-Kantian cosmopolitanism today: John Rawls and Jürgen Habermas on Immanuel Kant's foedus pacificum. The King's College Law Journal 15: 5-22, 2004.

HABERMAS, J. Strukturwandel der Öffentlichkeit. 4.Aufl., Frankfurt am Main, Suhrkamp Verlag, 1995.

_Die Einbeziehung des Anderen. Studien zur politischen Theorie. 2.Aufl., Frankfurt am Main, Suhrkamp Verlag, 1997.

HELD, D. Democracy and the Global Order. Stanford: Stanford University Press, 1995.

KANT, I. Kants Gesammelte Schriften. Hrsg. von der Königlichen Preussischen, bzw. von der Deutschen Akademie der Wissenschaften. Berlin: Walter de Gruyter, 1902 ss.

_Immanuel Kants Werke. Herausgegeben von Ernest Cassirer, Berlin, Bruno Cassirer, 11 v., 1922.

KLEINGELD, P. Kant's Cosmopolitan Patriotism. Kant-Studien 94: 299-316, Walter de Gruyter, 2003.

KLENNER, H. Kants Entwurf "Zurn ewigen Frieden" - Illusion oder Utopie? Archiv für Rechts- und Sozialphilosophie, 2: 151-160, 1996.

MERTENS, T. "Cosmopolitanism and citizenship: Kant against Habermas", European Journal of Philosophy, 4 (1996), 328-47.

MORI, M. La pace e la ragione. Kant e le relazioni internazionali: diritto, politica e storia. Bologna: II Mulino, 2008.

ROUSSEAU, J-J. Projet de constitution pour la Corse. La gaya scienza, 2012.

SCHMITT, C. Der Begriff des Politischen. Duncker und Hunblod: Berlin, 1979.

SCRIVENER, M. The Cosmopolitan Ideal in the Age of Revolution and Reaction, 1776-1832. New York: Pickering and Chatto, 2007.

VELASCO ARROYO, J. C. Ayer y hoy del cosmopolitismo kantiano. Madrid: 
Isegoría,16: 91-117, 1997.

1 Lista de abreviaturas: Zef, Zum ewigen Frieden; MdS, Methaphysic der Sitten; TuP, Über den Gemeinspruch: Das mag in der Theorie richtig sein, taugt aber nicht für die Praxis; BdF: Beantwortung der Frage: Was ist Aufklärung?; IGA: Idee zu einer allgemeinen Geschichte in weltbürgerlicher Absicht; RGV, Die Religion innerhalb der Grenzen der bloßen Vernunft.

${ }^{2}$ Habermas interpreta que o conceito kantiano de república corresponde ao que se denomina atualmente de estado democrático de direito.

3 O conceito de "guerra total" foi introduzido por Carl Schmitt no Corolário II, intitulado "Sobre a relação entre os conceitos de guerra e inimigo", incorporado a O conceito do político em 1938 (SCHIMITT, P. 94), mas a sua paternidade é muitas vezes atribuída erroneamente ao discurso pronunciado em 18 de fevereiro de 1943pelo ministro da propaganda nazista Joseph Goebbels.

${ }^{4}$ A maioria dos contratualistas da Modernidade, entre eles Hobbes e Locke, pensava que a América ainda estava em estado de natureza.

${ }^{5}$ Habermas associa o surgimento das repúblicas nos EUA e na França com o estado democrático de direito.

${ }^{6}$ Pouco antes de Habermas publicar este artigo, o Conselho de Segurança das Nações Unidas criou o Tribunal Penal Internacional para a antiga lugoslávia, em 1993, o qual julgaria as supostas violações ocorridas nesta região contra a Convenção de Genebra, de 1949, e, embora tivesse caráter ad hoc, representou que o caso dos nazistas não se constituísse mais na única exceção de julgamento de pessoas acusadas de crime de guerra. Além do mais, depois que Habermas publicou este artigo apareceram instituições que corroboram o seu ponto de vista, como o Tribunal Penal Internacional, em 2002, com sede em Haia.

${ }^{7}$ A ideia do surgimento de um sistema financeiro aparece originariamente no Projeto de constituição para a Córsega de Rousseau. Embora Kant não cite explicitamente o genebrino, contudo, os termos que ele usa indica que esta ideia provém de sua leitura de Rousseau. Rousseau afirma que "Les systèmes de finances sont des inventions modernes" (ROUSSEAU, 2012, p. 45), enquanto Kant diz que "gesicherter Schulden - die sinnreiche Erfindung eines handeltreibenden Volks in diesem Jahrhundert". (KANT, ZeF, p. 345). Contudo, há uma diferença fundamental entre ambas as perspectivas, enquanto Rousseau projetava a sua reforma social voltada para o passado, ele indicava que o sistema financeiro surge na Modernidade porque os cidadãos na Antiguidade não pagavam impostos, enquanto Kant, pensando na reforma social que virá, considera que este sistema financeiro se tornou internacional e uma fonte de alimentação do endividamento dos estados em sua preparação para a guerra futura.

${ }^{8}$ Naturalmente que houve um recrudescimento do nacionalismo nos países africanos e asiáticos que resultaram do processo de descolonização. 